\title{
Effort or timing: The effect of lump-sum bonuses
}

\author{
Thomas J. Steenburgh
}

Received: 16 July 2007 / Accepted: 21 May 2008 / Published online: 26 June 2008

(C) Springer Science + Business Media, LLC 2008

\begin{abstract}
This article addresses the question of whether lump-sum bonuses motivate salespeople to work harder to attain incremental orders or whether they induce salespeople to play timing games (behaviors that increase incentive payments without providing incremental benefits to the firm) with their order submissions. We find that lump-sum bonuses primarily motivate salespeople to work harder-a result that is consistent with the widespread use of bonuses in practice, but that contradicts earlier empirical work in academics.
\end{abstract}

Keywords Sales force incentives $\cdot$ Compensation methods

JEL Classification $\mathrm{G} 30 \cdot \mathrm{J} 31 \cdot \mathrm{J} 33 \cdot \mathrm{L} 23 \cdot \mathrm{M} 31 \cdot \mathrm{M} 41 \cdot \mathrm{M} 52$

\section{Introduction}

Those who manage salespeople commonly believe that lump-sum bonuses are effective motivators. A recent field survey (Joseph and Kalwani 1998) finds that $72 \%$ of firms use bonuses in their sales incentive contracts, whereas only $58 \%$ use commission rates, the next most common form of incentive pay. ${ }^{1}$ Moynahan (1980, p. 149) states in his book on designing effective sales incentive contracts that "for the majority of industrial sales positions, [lump-sum bonuses are] probably the optimum form of compensation." While lump-sum bonuses are not considered to be the only sound way to motivate salespeople, they are widely regarded in the trade

\footnotetext{
${ }^{1}$ Joseph and Kalwani (1998) also find that 35\% of firms include both bonuses and commission rates and $5 \%$ offer salary alone.

Thomas J. Steenburgh is an Associate Professor at the Harvard Business School. He would like to thank Andrew Ainslie, Subrata Sen, and K. Sudhir for comments and suggestions that greatly improved the quality of this article. He is especially grateful for the advice and encouragement of his late thesis advisor, Dick Wittink. The author, of course, is solely responsible for remaining errors.
}

T. J. Steenburgh $(\bowtie)$

Harvard Business School, Soldiers Field, Boston, MA 02163, USA

e-mail: tsteenburgh@hbs.edu 
literature (Agency Sales Magazine, Sep 2001; Bottomline, Oct 1986) and in textbooks on sales compensation planning (Churchill et al. 2000) as effective motivators.

Given the business world's preoccupation with lump-sum bonuses, it is interesting to note that academics are divided as to their effectiveness. Two main arguments are advanced against their use. First, as Holmstrom and Milgrom (1987) and Lal and Srinivasan (1993) point out, the motivational effects of lump-sum bonuses disappear once sales quotas have been met and incentives have been earned. "It is not uncommon," write Lal and Srinivasan, "to hear of salespeople spending time playing golf or indulging in other leisurely activities if their past efforts have been unusually successful." 2 A flat commission rate, on the other hand, should not induce such fluctuations in behavior since the incentive to work is constant over time and independent of how well or poorly an individual has performed in the past.

Second, as Oyer (1998) and Jensen (2003) point out, lump-sum bonuses tempt salespeople to manipulate the timing of orders to meet sales quotas without having to expend additional effort. This type of behavior can take two forms. Salespeople who have already made quota are encouraged to push out new orders to the next period to make attaining future quotas easier to accomplish, a behavior termed delayed selling. On the other hand, salespeople who would otherwise fall short of their current quota are encouraged to pull in orders from the next period, a behavior termed forward selling. These behaviors are in conflict with the firm's interest because they result in higher incentive costs without returning concomitant gains.

Adverse consequences notwithstanding, some academics maintain that lump-sum bonuses are effective motivators. Darmon (1997), among others, makes the point that providing bonuses encourages individuals to reach for sales targets that they otherwise might not attain.

The rationale for such plans is simple and well known: Quotas are set so as to provide salespeople with objectives that are challenging and worth being achieved. In order to enhance salespeople's performance, management grants them some reward when they reach a pre-specified performance level (the quota) which is higher than the level they would have achieved otherwise.

Attention to the study of how goals, such as sales quotas, affect motivation dates to the experimental work of Hull $(1932,1938)$ and Mace (1935). Latham and Locke (1991) present the findings of hundreds of subsequent studies in the goal-setting literature. McFarland et al. (2002) discuss how multiple quotas affect sales call selection; Darmon (1997) discusses what influences management to select specific bonus contract structures; and Mantrala et al. (1994) use agency theory to develop an approach for determining optimal bonus contracts.

These arguments for and against lump-sum bonuses suggest the basic question that must be asked by firms considering whether to offer them: will the productive gains from increased effort outweigh the counterproductive losses? This question is not entirely new to marketing since the same basic concern applies to the promotion of consumer packaged goods. Just as bonuses can motivate either productive effort or unproductive timing games, consumer promotions can increase demand either

\footnotetext{
${ }^{2}$ This argument is not limited to bonuses; other nonlinear incentive contracts, such as tiered commission rates, share the disadvantage of not offering constant motivation to work.
} 
Table 1 Bonus plan effects across industries

\begin{tabular}{lll}
\hline Industry & $\begin{array}{l}\text { Increase Due } \\
\text { to Bonus }\end{array}$ & $\begin{array}{l}\text { Decrease Due } \\
\text { to Bonus }\end{array}$ \\
\hline Office Machines & $4.3 \%$ & $-4.4 \%$ \\
Computers & $5.3 \%$ & $-6.4 \%$ \\
Optical Supplies & $6.2 \%$ & $-4.1 \%$ \\
\hline
\end{tabular}

through increased consumption (primary demand) or through brand switching (secondary demand). Gupta (1988), Van Heerde et al. (2003), and Steenburgh (2007) are among many others who have addressed this issue in the promotions literature.

Although much attention has been given to consumer promotions, little empirical work has been devoted to the effects of sales incentive contracts. A notable exception is Oyer (1998), who provides empirical evidence that nonlinear incentive contracts induce temporal variation in firms' output. Using firm-level data across many industries, Oyer finds that firms' reported revenue tends to increase in the fourth quarter and to dip in the first quarter of their fiscal years. This result is consistent with the notion that some agents of the firm, whether salespeople or executives, are varying effort, manipulating the timing of sales, or both in response to annual incentive contracts. As the magnitude of the spikes and dips are roughly equivalent in Oyer's analysis (see Table 1 for estimates from a few industries), we might infer that timing games play a particularly important role.

In contrast, this study suggests that lump-sum bonuses primarily motivate salespeople to work harder. Our results are based on a unique dataset that differs from Oyer's (1998) in several important respects. First, it offers a more refined view of how salespeople behave because it is based on individual-level rather than firmlevel output. This is an important distinction because theory suggests that some salespeople should game the system by delaying sales and others by moving sales forward at a given point in time. It is not possible to simultaneously observe the effects of both behaviors on sales using aggregate data. ${ }^{3}$ Second, whereas Oyer does not directly observe the firms' incentive contracts and reasonably assumes that incentives are offered at the fiscal-year end, we do observe the contracts under which salespeople work. We show that directly observing the structure and timing of incentives is critical to understanding whether greater effort or timing games explain the resulting variation in output. Finally, we observe the output of a group of salespeople who lack incentives to concentrate production at the end of quarters, and we use this group's output use to control for temporal variation not attributable to the incentive contract, such as customer buying cycles.

Our results suggest that salespeople respond rationally to incentives because individuals work harder when they have more to gain by doing so. They also suggest that the widespread practice of using lump-sum bonuses may not be as detrimental to firms as some believe because their primary effect can be to motivate people to work harder rather than to play timing games.

\footnotetext{
${ }^{3}$ At best, it may be possible to observe the effect of the dominant behavior, either delayed or forward selling, on sales using aggregate data; still, given that these two behaviors produce opposing effects, it may also be possible that both behaviors occur, but their effects on sales cancel out when the data are aggregated.
} 


\section{Literature review}

An extensive theoretical literature in marketing and economics, usually focused on finding an optimal incentive contract under a given set of conditions, explores how various incentive contracts affect worker motivation. Basu et al. (1985), Rao (1990), Lal and Srinivasan (1993), Joseph and Thevaranjan (1998), Gaba and Kalra (1999), and Godes (2004), among others, examine issues directly related to sales incentive strategy. Several of these studies examine how sales incentive contracts influence effort, but none explore timing effects. Gaba and Kalra's (1999) experimental evidence supports theoretical predictions about how salespeople should respond to lump-sum bonuses, but they focus on whether salespeople should engage in more risky selling behavior rather than whether salespeople should put forth more effort.

Chevalier and Ellison (1997) suggest that a relatively small empirical literature on how people respond to incentives exists because the direct observation of incentive contracts is rare. Coughlan and Sen (1986), John and Weitz (1989), Coughlan and Narasimhan (1992), and Misra et al. (2005) explore sales force incentive issues using survey data, but focus on firms' decisions (e.g., what mix of salary and incentive to offer) rather than the behavior of salespeople. Banker et al. (2000) and Lazear (2000) find, respectively, that salespeople and factory workers increase productivity in response to pay-for-performance incentive contracts. These studies, being based on piece-rate incentive contracts that should curb such behavior, do not explore timing effects. Healy (1985) finds that managers alter accrual decisions (a timing effect) in response to their incentive contracts, but does not examine how these contracts affect the managers' productivity. Our study provides a more comprehensive view of behavior by examining workers' effort and timing decisions under a directly observed incentive contract.

\section{Institutional details}

The focal firm is a Fortune 500 company that manufactures, sells, finances, and maintains durable office products. Its products range in complexity from relatively simple machines that sit on a desktop to fairly sophisticated ones that fill a room. Prices range from less than one thousand dollars to several hundred thousand dollars per machine. In addition to its physical products, the firm offers services such as equipment maintenance, labor outsourcing, and systems consulting. The firm's customers include major corporations, small businesses, and government agencies.

The firm directly employs ${ }^{4}$ the salespeople in this study, and it broadly classifies them as either account managers or product specialists. The account managers are responsible for selling basic products and for spotting opportunities in which the product specialists may be able to sell more sophisticated ones. There are several types of product specialists, each having distinct product-line expertise. Organizationally, the account managers make up one sales force, and the specialists are

\footnotetext{
${ }^{4}$ An indirect sales channel exists to reach small and rural accounts. It is composed of roughly eight hundred smaller firms that resell the focal firm's products through "arm's length" transactions. The focal firm, for example, cannot directly compensate the salespeople that work in the indirect channel. 
divided into the remaining sales forces by their product expertise. Although several salespeople may serve an account, each has unique responsibility and, as a rule, only one salesperson receives credit for the sale of a given product. The firm's culture frowns upon team compensation, and very few salespeople share territories.

The structure of the incentive contract, which is consistent across all of the sales forces, is outlined in Table 2. The salespeople's incentive pay is based on the amount of revenue that they produce for the firm. The contract includes three quarterly bonuses, a full-year bonus, a base commission rate, and an overachievement commission rate. The values of the commission rates and bonuses are common within a sales force, but vary across them. The sales quotas are specific to individual salespeople. The bonuses and tiered commission rates create a nonlinear relationship between the output of the salesperson and the incentive pay that they earn. Roughly half of the salespeople's pay is distributed through salary and the other half through incentives. We make no claim that this is an optimal incentive contract, but rather take it as given. Given the survey work of Joseph and Kalwani (1998), this structure appears to represent what is commonly found in practice.

The firm views a salesperson as having had a successful year if the full-year sales quota has been met, and the incentive contract places the greatest emphasis on this target. The sum of the three quarterly bonuses is worth just slightly more than the single full-year bonus, and the overachievement commission rate further emphasizes its importance to the firm. Long-term incentives outside of the sales incentive contract, such as promotions to better job assignments, grade-level increases, and salary increases, also depend in part on whether the full-year quota has been met. These extra-contractual incentive decisions do not depend on the satisfaction of quarterly quotas.

\section{Preliminary aggregate analysis}

Taking a preliminary view of the problem, we estimate a model based on sales-force level data. The intent of this analysis is twofold. First, it helps explain why Oyer's (1998) results, which are based on a dataset in which the incentive contracts are not directly observed, do not necessarily provide evidence of timing games. Specifically, we show that we cannot draw meaningful conclusions about whether gains in revenue at the fiscal-year end exceed losses in the subsequent period unless we also account for the effects of bonuses from interim periods (such as quarterly bonuses).

Table 2 Elements of the incentive contract

\begin{tabular}{|c|c|}
\hline Element & Description \\
\hline $\begin{array}{l}\text { First-, Second-, and Third-Quarter } \\
\text { Bonuses }\end{array}$ & $\begin{array}{l}\text { A lump-sum, cash bonus awarded if the quarterly revenue } \\
\text { exceeds the quarterly quota }\end{array}$ \\
\hline Full-Year Bonus & $\begin{array}{l}\text { A lump-sum, cash bonus awarded if the full-year revenue exceeds } \\
\text { the full-year quota }\end{array}$ \\
\hline Base Commission Rate & Paid on every dollar of revenue brought in by the salesperson \\
\hline Overachievement Commission Rate & Paid on only the revenue brought in above the full-year quota \\
\hline
\end{tabular}


Table 3 Descriptive statistics for the sales forces

\begin{tabular}{lrlllc}
\hline & $\begin{array}{l}\text { Number of } \\
\text { Salespeople }\end{array}$ & $\begin{array}{l}\text { Average } \\
\text { Tenure } \\
\text { (months) }\end{array}$ & $\begin{array}{l}\text { Average Full- } \\
\text { Year Quota (\$K) }\end{array}$ & $\begin{array}{l}\text { 10th Percentile Full- } \\
\text { Year Quotas (\$K) }\end{array}$ & $\begin{array}{l}\text { 90th Percentile Full- } \\
\text { Year Quotas (\$K) }\end{array}$ \\
\hline AM & 1,512 & 77.5 & 1,298 & 703 & 1,868 \\
PS1 & 370 & 91.5 & 2,808 & 1,221 & 3,822 \\
PS2 & 224 & 116.3 & 2,911 & 1,576 & 4,573 \\
PS3 & 282 & 114.0 & 2,775 & 1,646 & 3,995 \\
PS4 & 92 & 88.8 & 3,499 & 1,863 & 4,932 \\
PS5 & 90 & 130.0 & 6,543 & 1,277 & 20,895 \\
\hline
\end{tabular}

Second, this analysis produces results based on "aggregate" data that can be compared with results based on individual-level data in a more refined analysis.

\subsection{The data}

Our study is based on 2,570 salespeople who worked in one of six sales forces. ${ }^{6}$ The data consist of 50,106 monthly observations taken from January 1999 to December 2001. The maximum number of observations per individual is 36 and the average number is 19.5. Each month of the observation period, we observe the actual revenue that an individual produces for the firm, the associated sales quota or quotas that need to be met, and the individual's tenure with the firm (measured by the number of months that a salesperson has been employed).

Summary information about the sales forces is reported in Table 3. Descriptive statistics include the number of individuals, the average tenure, and the average, 10th and 90th percentile sales quotas for each sales force. Account managers (AM) represent more than half of the salespeople in the study. Individuals in this group tend to have lower sales quotas than the product specialists (PS1-PS5) do because they sell the most basic products offered by the firm. While the account managers also tend to have less sales experience, they are not entry-level salespeople. Their average tenure with the firm is over six years, and most individuals have outside experience in sales before joining the company. The wide spread between the 10th and the 90th percentile sales quotas is due to a significant difference in the sales potential of individual sales territories.

Observing the incentives and the revenue production of individual salespeople is not enough to determine whether an incentive contract is causing the temporal variation in output. We need to control for the possibility that customer behavior explains the peaks and dips in revenue production rather than strategic changes in the salespeople's actions. For example, suppose the firm's customers tend to delay spending until the last month of every quarter. The spikes and dips in production

\footnotetext{
${ }^{5}$ We use data that are averaged across individuals in the sales forces, rather than sales force aggregates, in order to control for differences in population size. Sales force aggregates would be sensitive to the number of people working at any given time.

${ }^{6}$ Salespeople who worked in teams, with two or more people sharing quota responsibility and pooling the revenue for a given territory, were excluded from the study as these individuals' incentives might differ from those of the general population owing to the free-riding opportunity.
} 
Table 4 Preliminary analysis assuming year-end effects only

\begin{tabular}{lrr}
\hline & \multicolumn{1}{c}{ Value } & $P$ value \\
\hline (Intercept) & 11.6061 & 0.0000 \\
PS1 & 0.7099 & 0.0000 \\
PS2 & 0.6290 & 0.0001 \\
PS3 & 0.6217 & 0.0001 \\
PS4 & 1.1075 & 0.0000 \\
PS5 & 1.2450 & 0.0000 \\
FY & 0.1782 & 0.1396 \\
POST.FY & -0.3393 & 0.0064 \\
CONTROL.SALES & 0.1343 & 0.0314 \\
\end{tabular}

might then be attributed to market behavior rather than the salespeople's response to the incentive plan.

We use the revenue produced by the indirect sales channel as a covariate to control for this possibility. The member firms of the indirect channel are compensated such that the variation in their output over time can be attributed to market forces rather than to their incentive contracts. In the first two years of the study, firms worked under a flat commission rate, while in the final year they worked under a flat commission rate in conjunction with a monthly bonus. Thus, agents in this channel lack incentive to lump production at the end of quarters.

\subsection{Empirical analysis}

To analyze the data, we estimate the model

$$
y_{s t}=\alpha+\sum_{s=1}^{5} D_{s} * \alpha_{s}+X_{t} \beta_{t}+\varepsilon_{s t}, \varepsilon_{s t} \sim N\left(0, \sigma^{2}\right)
$$

The independent variable $y_{s t}$ represents the log of the average revenue produced by the salespeople in sales force $s$ in month $t$. We use log revenue so the effects are proportional rather then additive. $D_{s}$ is a dummy variable that takes the value one for product specialist $s \in\{1, \ldots, 5\}$; this yields sales-force-specific intercepts. $X$ is composed of the following explanatory variables: FY is a dummy variable that takes the value one in December, the month before the full-year bonus period closes. POST.FY takes the value one in January, the month after the full-year bonus period closes. These variables are zero in all other months. Similarly, Q is a dummy variable that takes the value one in March, June, and September, the months before the quarterly bonus periods close. POST.Q takes the value one in April, July, and October. These variables are zero in all other months. CONTROL.SALES ${ }^{7}$ is the average sales revenue generated by the indirect sales channel, the control population. This variable is standardized for ease of interpretation.

We present results for the model that include only year-end effects in Table 4 . The revenue production at the end of the bonus period marginally increases $\left(\beta^{F Y}=\right.$ 0.1782), signifying that the incentive plan has a positive influence on the salespeople's behavior, but it is exceeded in magnitude by the decrease in revenue

\footnotetext{
${ }^{7}$ For future research, additional controls might be found by tracking customers' fiscal calendars, which could be used to infer their buying cycles. These data, however, were not available for this analysis.
} 
Table 5 Preliminary analysis with effects for all bonus periods

\begin{tabular}{lrr}
\hline & \multicolumn{1}{c}{ Value } & $P$ value \\
\hline (Intercept) & 11.4090 & 0.0000 \\
PS1 & 0.7028 & 0.0000 \\
PS2 & 0.5685 & 0.0000 \\
PS3 & 0.5522 & 0.0000 \\
PS4 & 1.0678 & 0.0000 \\
PS5 & 1.1482 & 0.0000 \\
FY & 0.5694 & 0.0004 \\
POST.FY & -0.3749 & 0.0077 \\
Q & 0.2476 & 0.0118 \\
POST.Q & 0.1054 & 0.2257 \\
CONTROL.SALES & 0.2624 & 0.0000 \\
\hline
\end{tabular}

after the bonus period ends $\left(\beta^{\text {POST.FY }}=-0.3393\right)$. The coefficient for the year-end increase is not statistically significant. From a broad perspective, these estimates appear similar to Oyer's and may lead us to conclude that the incentive contract encourages salespeople only to forward sell, not to work harder.

Given that the quarterly bonuses are of lesser value than the full-year bonus, we might not expect their inclusion to make a significant impact. Yet, when looking at the results in Table 5 for the model including both quarterly and full-year effects, the picture is now quite different. The positive effects during the bonus periods outweigh the negative effects afterwards. In fact, we do not find evidence of a dip in revenue after the quarterly bonus periods end, as $\beta^{\text {POST.Q }}$ is insignificant. For the full-year bonus, the dip in revenue after the period explains $41 \%$ of the increase in revenue during the period. ${ }^{8}$ These results suggest the primary influence of the incentive contract is to encourage salespeople to work harder, not to play timing games.

What causes the results to change so dramatically? The baseline sales level is overestimated by omitting the quarterly effects because the productive increases in revenue at quarters' end are not followed by counterproductive decreases. Since the quarterly effects do not merely cancel each other out, but rather are positive, the intercept of the $\log$ of revenue drops from 11.6 to 11.4 when we include them. As can be seen in Fig. 1, this affects the parameter estimates and changes our interpretation of the year-end effects. By not accounting for the quarterly bonuses, we underestimate the spike in revenue caused by the full-year bonus and overestimate the dip in revenue following it.

The preliminary analysis illustrates the need for careful modeling, but it brings up as many questions as it answers. Most importantly, we have not accounted for differences in individuals' circumstances that may have an equally important impact on our results. For example, while an individual who has already made a bonus is encouraged to delay sales, an individual who has not yet made it is encouraged to forward sell. Do these effects cancel one another out or does one effect tend to

\footnotetext{
${ }^{8}$ The proportion of the spike in revenue during the bonus period explained by the dip in revenue afterwards is calculated as $\left|e^{\beta^{F Y . P O S T}}-1\right| /\left(e^{\beta^{F Y}}-1\right)$. 
Fig. 1 Preliminary model comparison

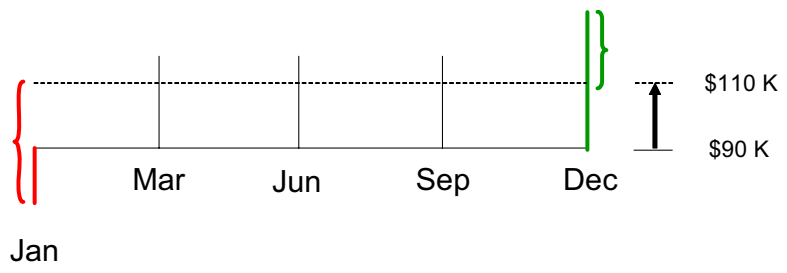

dominate? How does this affect our analysis of whether effort or timing effects are more important? We now discuss how an individual's sales history can influence her or his actions and build an individual-level model to capture these effects.

\section{Theoretical motivation}

Principal-agent models give us an appreciation of how individuals respond to various circumstances. In this section, we discuss the ways we would anticipate a salesperson responding given various levels of accumulated sales within a bonus period. Specifically, we focus on how past performance influences an individual's decision to work and to play timing games. Our conclusions will suggest that an accurate decomposition of effort and timing effects cannot be made without accounting for individual-level behavior. This motivates the development of a statistical model based on individual-level data.

\subsection{Effort}

Lal and Srinivasan (1993) point out that past performance influences the level of effort exerted when a salesperson is working under a bonus contract. A simple example helps clarify this relationship. Consider a salesperson who is working to achieve a quarterly bonus. Each month she has the opportunity to sell one unit of a good. By working harder she increases the probability of a sale, but greater effort comes at an increasing marginal cost. Let $\theta_{t}$ be the probability of a successful sale and $\theta_{t / 2}^{2}$ be the associated cost of effort in month $t \in\{1,2,3\}$. Suppose that the salesperson's utility for wealth is $u(w)$. Suppose further that the firm offers a salary of $a$ no matter what the salesperson produces and a bonus of $b$ if the salesperson meets or exceeds a quota of $q=2$ units. Let $\Delta \equiv u(a+b)-u(a)$ be the difference in utility between earning and not earning the bonus without regard to the cost of effort.

Figure 2 illustrates how the salesperson's past performance affects the level of effort exerted in the final month of the quarter. First, consider a salesperson who does not complete a sale in either of the first two months. She has no chance of making her quota and earning the bonus; consequently, she chooses not to work in month three, a marginal decrease in effort from the second period level. Next, consider a salesperson who completes sales in both of the first two months. She has already made quota and earned the bonus; consequently, she also chooses not to work in month three, a marginal decrease in effort from the second period level. Finally, consider a salesperson who completes one sale in the first two periods. The 
Fig. 2 Effort in month three given accumulated sales

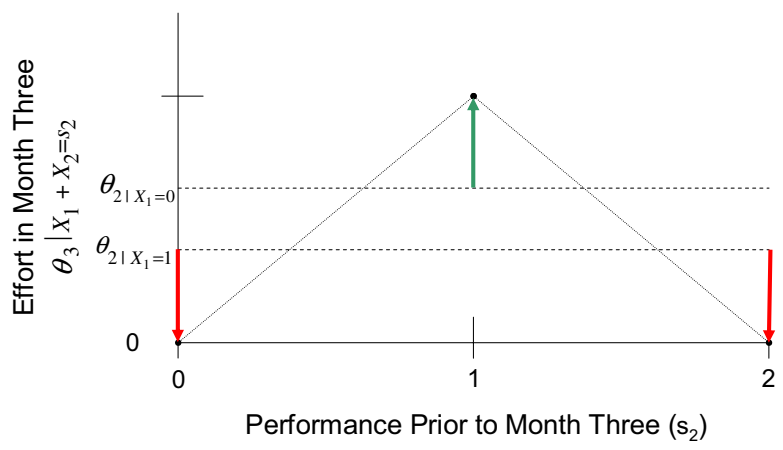

third period provides the final opportunity for her to make quota; consequently, she marginally increases effort from the second period level. (Proof in Appendix I.)

Despite being simple, this model provides the basic intuition of how individuals vary effort when working under a bonus contract. As illustrated in Fig. 2, those who are within reach of the bonus work harder; those who have already earned the bonus relax; those who cannot earn the bonus give up.

We summarize the predictions of how salespeople will behave and the corresponding influence of this behavior on revenue production (which we observe in the data) as follows:

Suppose a lump-sum bonus is the only incentive offered for quota attainment. In the final month of the bonus period:

a) salespeople who can make quota if they stretch will increase effort and their revenue production will marginally increase.

b) salespeople who either

1. have already made quota, or

2. are unlikely to make quota

will decrease effort and their revenue production will marginally decrease.

The firm analyzed in this paper offers an overachievement commission rate in conjunction with the full-year bonus. This commission rate will modify how a salesperson who has already made quota behaves, but it will not influence the other salespeople. Returning to the previous example, suppose the firm offers an additional incentive $c$ if the salesperson sells one unit more than her quota. She now will exert positive effort in the third month if she sold a unit in each of the first two periods, but she still exerts no effort if she did not sell a unit in each of the first two periods. (See Fig. 3) Given the overachievement commission rate, we make no prediction about whether salespeople who have met quota will marginally increase or decrease effort.

\subsection{Timing games}

Just as past performance influences how hard an individual is willing to work for a bonus, it affects the types of timing games that he or she plays with orders. Oyer (1998) builds a simple theoretical model to predict how individuals manipulate the 
Fig. 3 The effect of an overachievement commission rate

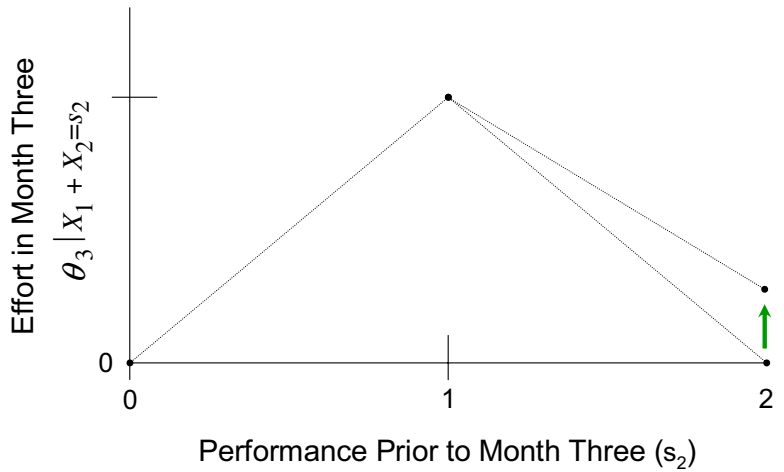

timing of sales, essentially showing that salespeople will pull in orders from future periods if they would otherwise fall short of a sales quota and they will push out orders to future periods if quotas are either unattainable or have already been achieved. The timing-game predictions correspond to the effort predictions as follows:

Suppose a lump-sum bonus is the only incentive offered for quota attainment. In the final month of the bonus period:

a) salespeople who can make quota if they stretch will pull in sales from future periods. Their revenue production will marginally increase in the month before and will marginally decrease in the month after the bonus period closes.

b) salespeople who either

1. have already made quota, or

2. are unlikely to make quota

will push out sales to future periods. Their revenue production will marginally decrease in the month before and will marginally increase in the month after the bonus period closes.

The timing-game predictions raise the issue of whether it is even possible to decompose the effort and timing effects using aggregate data. For instance, suppose one group of salespeople is forward selling and another, of equal size, is delaying sales. In aggregate, we would see no change in output, as the spikes in output of one group are perfectly balanced by the dips in output of another. Orders are being moved across periods, but we cannot identify the counterproductive behavior from the data because they move equally in both directions. We now turn to developing a statistical model that takes into account an individual's distance from quota so as to accurately identify the timing and effort effects.

\section{Model development}

\subsection{Defining the sales history variables}

The theoretical discussion highlights why we need to account for past performance if we are to accurately decompose the effort and timing effects. The implementation 
of this, however, is made difficult by the nonlinear relationship between past performance and how an individual behaves. For example, if prior outcomes are poor, the salesperson reduces effort near the end of a bonus period. If he or she is within striking distance of quota, the salesperson increases effort. Yet, if the quota has already been made, the salesperson reduces effort.

We use categorical variables to capture how past performance affects an individual's revenue production. The variables are created using the individuals' performance to date (PTD) against quota immediately prior to the final month of a bonus period. For every month that a salesperson works, we observe the sales quota or quotas that need to be met and the actual amount of revenue produced by the individual. An individual's PTD is defined as the ratio of cumulative revenue produced in a bonus period to the quota that needs to be met. For example, if a salesperson's first-quarter quota is $\$ 400 \mathrm{~K}$ and she has produced $\$ 200 \mathrm{~K}$ in total at the end of February, the PTD is $50 \%$ against the first quarter quota at that point in time.

Two sets of categorical variables are needed to capture the effects of sales history on revenue production: one set of variables for the month before a bonus period and one set for the month following a bonus period. The categorical variables are: EXCEEDED, NEAR, STRETCH, FAR, and REMOTE in the month before the end of an incentive period; and POST.EXCEEDED, POST.NEAR, POST.STRETCH, POST.FAR, and POST.REMOTE in the month after it. (Note: we add two additional categories, VERY.FAR and POST.VERY.FAR, for the full-year bonus period because distribution of past performance is wider.) We refer to these as the sales history variables and their definitions, which are based on the PTD measure, are given in Table 6. We estimate the quarterly and full-year effects separately because the amount of compensation at stake is greater at the end of the year than it is at the end of a quarter. The observed frequency of occurrence for each of the categories is given in Fig. 4.

An example clarifies how these variables are defined. Suppose a salesperson has done very well and her PTD is $120 \%$ at the end of February. In March, the variable EXCEEDED associated with the quarterly quotas takes the value one and variables NEAR, STRETCH, FAR, and REMOTE take the value zero for this salesperson. In April, all of the aforementioned variables take the value zero; the variable POST. EXCEEDED associated with the quarterly quotas takes the value one; and the variables POST.NEAR, POST.STRETCH, POST.FAR, and POST.REMOTE take the value zero. (The POST variables take the value zero in March, and all of the variables take the value zero in months not surrounding a quarterly bonus.) A similar process is used to define the quarterly variables in June, July, September, and October and to define the full-year variables in December and January.

Table 6 Definition of Sales History Variables

Several alternative definitions of these variables were tested; none resulted in substantive changes to the findings.

\begin{tabular}{lll}
\hline Variable & $\begin{array}{l}\text { Quarterly } \\
\text { performance to date }\end{array}$ & $\begin{array}{l}\text { Full-year } \\
\text { performance to date }\end{array}$ \\
\hline EXCEEDED & $\geq 1$ & $\geq 1$ \\
NEAR & $2 / 3-1$ & $11 / 12-1$ \\
STRETCH & $1 / 3-2 / 3$ & $8 / 12-11 / 12$ \\
FAR & $0-1 / 3$ & $4 / 12-8 / 12$ and $0-4 / 12$ \\
REMOTE & $\leq 0$ & $\leq 0$
\end{tabular}


Fig. 4 Observed frequency of categories

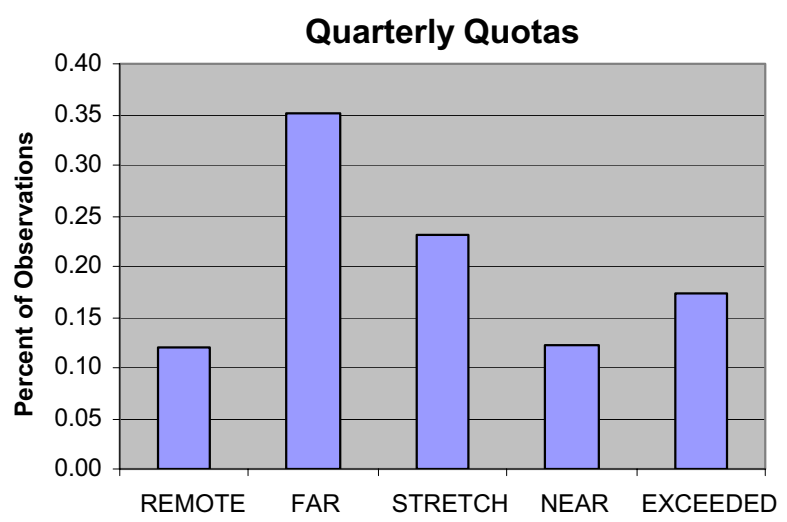

Full-Year Quota

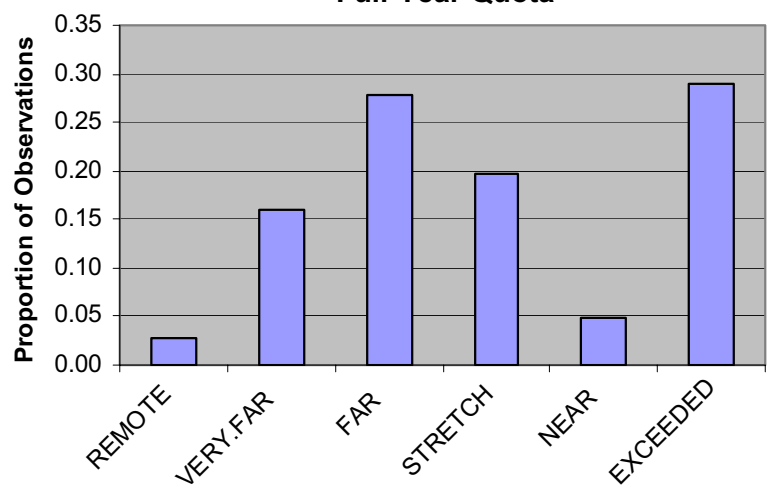

How do we know whether individuals are playing timing games or exerting greater effort? Timing games imply that salespeople move orders from one period to the next. Subsequently, spikes (dips) in revenue production in the month prior to the close of a bonus period are followed by equivalent dips (spikes) in production in the month after it. On the other hand, if the salespeople are just varying effort, spikes or dips in production exist in the month prior to the close of an incentive period, but not in the month after it. In other words, we infer whether timing games are being played by the sign of the coefficient of the POST variables.

\subsection{The regression model}

We model the revenue production of salesperson $i$ from sales force $s$ in month $t$ as follows:

$$
\begin{gathered}
y_{s i t}=\alpha_{s i}+X_{s i t} \beta_{s}+\varepsilon_{s i t}, \varepsilon_{s i t} \sim N\left(0, \sigma_{s i}^{2}\right) \\
\alpha_{s i} \sim N\left(\xi_{s}, \sigma_{\alpha s}^{2}\right)
\end{gathered}
$$




$$
\begin{gathered}
\xi_{s} \sim N\left(\gamma, \sigma_{\xi}^{2}\right) \\
\beta_{s} \sim \operatorname{MVN}_{p}(\delta, \Sigma)
\end{gathered}
$$

where $s=1, \ldots, 6 ; i=1, \ldots, n_{s} ; t \in\{1, \ldots, 36\}$. An individual is identified by two subscripts, $s$ and $i$, in this notation. The constant $n_{s}$ denotes the number of individuals in sales force $s$. The month $t$ refers to a specific calendar month; this is necessary to identify the market sales, a variable in the vector $X_{\text {sit }}$. A salesperson's output is measured in thousands of dollars of revenue produced for the firm. The variance of the error term is assumed to be individual specific. (See Appendix II for the full conditional posterior distributions.)

Differences among the individual salespeople are accounted for through the random intercepts $\alpha_{s i}$. Since individuals within a sales force have many common characteristics - for example, they sell the same types of products, share common managers, undergo similar training, etc.- we model the intercepts as arising from a sales-force-specific distribution. In turn, the means of the sales-force-specific distributions, $\xi_{s}$, are modeled as arising from a common population distribution. The intercepts $\alpha_{s i}$ are interpreted as an individual's baseline revenue production.

The vector of explanatory variables, $X_{\text {sit }}$, includes tenure with the firm, market sales (measured by the revenue produced in the indirect channel), and the categorical variables describing an individual's sales history at that point in time. The sales-forcespecific parameters $\beta_{s}$ quantify the influence of these variables. Since the sales history variables are categorical, we can interpret the coefficients associated with these variables as marginal changes in an individual's revenue production from her or his baseline. We model the parameters $\beta_{s}$ as arising from a common population distribution. Our specification allows us to draw inference at both the sales force and population levels.

We decompose the marginal changes in revenue production into effort and timing-game components using the following relationships: Let $\Delta$ be the marginal change in revenue production attributable to effort and let $\Lambda$ be the change attributable to timing games. For any given sales history, say for individuals in the STRETCH classification, $\Delta$ and $\Lambda$ are defined as:

$$
\begin{aligned}
& \Delta^{\text {STRETCH }}=\delta^{\text {STRETCH }}+\delta^{\text {POST.STRETCH }} \\
& \Lambda^{\text {STRETCH }}=-\delta^{\text {POST.STRETCH }} .
\end{aligned}
$$

It is straightforward to find these quantities through the Markov chain Monte Carlo (MCMC) output.

\section{Results}

We summarize the results from Eq. 2 using the mean and standard deviation of the posterior distributions. The population-level results are reported in Table 7 and the sales-force-level results in Table 8 . The incentive contracts generally motivate 
Table 7 Population parameter estimates

\begin{tabular}{|c|c|c|c|}
\hline & Variable & Coefficient & SD \\
\hline Intercept & & 70.8 & 11.0 \\
\hline \multirow[t]{10}{*}{ Quarterly } & Exceeded & 38.7 & 7.6 \\
\hline & Near & 24.3 & 7.4 \\
\hline & Stretch & 12.7 & 7.1 \\
\hline & Far & -2.9 & 5.9 \\
\hline & Remote & -7.5 & 6.9 \\
\hline & Post.exceeded & 11.6 & 7.0 \\
\hline & Post.near & 3.8 & 7.3 \\
\hline & Post.stretch & 2.2 & 6.0 \\
\hline & Post.far & 0.0 & 5.6 \\
\hline & Post.remote & 1.0 & 6.7 \\
\hline \multirow[t]{12}{*}{ Full-Year } & Exceeded & 92.4 & 10.1 \\
\hline & Near & 59.4 & 12.4 \\
\hline & Stretch & 80.5 & 10.9 \\
\hline & Far & 49.0 & 9.3 \\
\hline & Very.far & 22.6 & 15.3 \\
\hline & Remote & -25.8 & 13.1 \\
\hline & Post.exceeded & -9.6 & 8.0 \\
\hline & Post.near & -11.3 & 12.4 \\
\hline & Post.stretch & -10.8 & 8.2 \\
\hline & Post.far & -0.8 & 7.4 \\
\hline & Post.very.far & -2.6 & 8.7 \\
\hline & Post.remote & -6.0 & 14.2 \\
\hline Tenure & & 0.6 & 4.6 \\
\hline Control.sales & & 19.6 & 5.6 \\
\hline
\end{tabular}

salespeople to produce more revenue during the bonus period. See the EXCEEDED coefficients, for example, in Table 7 . We now turn to discussing whether effort or timing games lead to the increases.

\subsection{Timing games}

Very limited support exists for the idea that the salespeople play timing games in response to bonuses at this firm. When considered individually, none of the POST variables are statistically significant at the population level (see Table 7). This holds for both the quarterly and the full-year bonus periods. We also consider the weighted-average of the post-period effects, where the weights are determined by the observed frequency of a given sales history. When taken as a group, the $90 \%$ credible intervals of the weighted means are $(-1.9,8.2)$ for the quarterly effects and $(-12.3,0.3)$ for the full-year effects. Since both intervals contain zero, no support exists for timing games on this measure either.

This is surprising for a few reasons. Salespeople who sell durable goods should be able to influence the timing of sales more directly than their consumer goods counterparts because each sale requires considerable time and intense customer contact. We would expect that these salespeople would have some ability to manipulate the timing of business. Second, a sizeable portion of the focal firm's business comes from customers trading in old equipment. This should make it easier for salespeople to delay the timing of sales because not all customers have a pressing need for new equipment. 
Table 8 Sales force parameter estimates

\begin{tabular}{|c|c|c|c|c|c|c|c|}
\hline & Variable & $\mathrm{AM}$ & PS1 & PS2 & PS3 & PS4 & PS5 \\
\hline \multirow[t]{2}{*}{ Intercept } & & 63.5 & 87.6 & 66.1 & 58.3 & 96.4 & 54.2 \\
\hline & & 2.0 & 4.2 & 6.0 & 5.8 & 12.2 & 11.2 \\
\hline \multirow[t]{20}{*}{ Quaterly } & \multirow[t]{2}{*}{ Exceeded } & 38.6 & 28.8 & 38.6 & 43.7 & 41.5 & 43.9 \\
\hline & & 4.0 & 5.1 & 9.0 & 8.8 & 9.1 & 12.9 \\
\hline & \multirow[t]{2}{*}{ Near } & 24.6 & 16.7 & 17.1 & 29.1 & 29.9 & 29.4 \\
\hline & & 4.0 & 5.3 & 8.5 & 8.2 & 8.5 & 14.3 \\
\hline & \multirow[t]{2}{*}{ Stretch } & 15.2 & 8.4 & 0.5 & 4.9 & 18.2 & 28.1 \\
\hline & & 2.6 & 4.1 & 6.0 & 7.8 & 6.9 & 8.3 \\
\hline & \multirow[t]{2}{*}{ Far } & 3.8 & -8.4 & -3.4 & 0.5 & -8.5 & -0.1 \\
\hline & & 1.8 & 3.3 & 5.1 & 5.5 & 7.4 & 7.7 \\
\hline & \multirow[t]{2}{*}{ Remote } & -7.9 & -18.4 & -2.6 & -2.2 & -8.7 & -4.0 \\
\hline & & 3.8 & 5.5 & 6.8 & 6.5 & 11.4 & 8.0 \\
\hline & \multirow[t]{2}{*}{ Post.exceeded } & 7.5 & 13.7 & 14.9 & 10.9 & 15.8 & 10.1 \\
\hline & & 3.8 & 4.6 & 8.8 & 8.2 & 10.3 & 12.6 \\
\hline & \multirow[t]{2}{*}{ Post.near } & 0.4 & 6.1 & 8.3 & 0.7 & 6.9 & 5.3 \\
\hline & & 3.3 & 5.3 & 9.4 & 8.7 & 7.2 & 13.2 \\
\hline & \multirow[t]{2}{*}{ Post.stretch } & 5.3 & 1.0 & -2.5 & 4.9 & 5.5 & -3.2 \\
\hline & & 2.5 & 4.3 & 4.7 & 7.7 & 7.3 & 9.2 \\
\hline & \multirow[t]{2}{*}{ Post.far } & 0.8 & -5.0 & -1.8 & 2.7 & 3.6 & -1.6 \\
\hline & & 2.0 & 3.8 & 4.5 & 5.1 & 7.1 & 6.2 \\
\hline & \multirow[t]{2}{*}{ Post.remote } & 1.2 & -3.2 & 0.7 & 6.5 & 2.0 & -2.2 \\
\hline & & 3.5 & 5.7 & 6.1 & 6.6 & 9.5 & 7.6 \\
\hline \multirow[t]{24}{*}{ Full-Year } & \multirow[t]{2}{*}{ Exceeded } & 75.2 & 94.8 & 99.5 & 102.6 & 96.1 & 81.1 \\
\hline & & 5.5 & 7.8 & 13.5 & 12.6 & 11.5 & 17.3 \\
\hline & \multirow[t]{2}{*}{ Near } & 56.7 & 58.4 & 68.1 & 57.9 & 57.8 & 55.3 \\
\hline & & 10.3 & 11.2 & 15.5 & 14.1 & 15.1 & 17.4 \\
\hline & \multirow[t]{2}{*}{ Stretch } & 55.3 & 76.9 & 76.0 & 82.7 & 88.1 & 98.4 \\
\hline & & 4.4 & 5.7 & 11.2 & 10.9 & 15.0 & 16.5 \\
\hline & \multirow[t]{2}{*}{ Far } & 29.1 & 49.0 & 49.6 & 68.0 & 49.4 & 45.1 \\
\hline & & 4.5 & 6.1 & 8.7 & 11.3 & 10.3 & 15.0 \\
\hline & \multirow[t]{2}{*}{ Very.far } & 5.5 & 32.1 & 52.1 & 39.1 & 23.1 & -22.8 \\
\hline & & 3.6 & 10.8 & 13.2 & 11.8 & 19.6 & 13.9 \\
\hline & \multirow[t]{2}{*}{ Remote } & -30.5 & -18.2 & -9.4 & -22.2 & -26.8 & -43.9 \\
\hline & & 8.0 & 16.0 & 15.6 & 14.4 & 16.4 & 15.2 \\
\hline & \multirow[t]{2}{*}{ Post.exceeded } & -16.0 & -12.3 & -10.0 & -1.8 & -5.2 & -5.9 \\
\hline & & 4.6 & 6.5 & 8.7 & 10.2 & 11.2 & 14.5 \\
\hline & Post.near & -16.1 & -16.1 & 2.5 & -2.8 & -10.1 & -18.0 \\
\hline & & 7.5 & 11.5 & 12.9 & 15.6 & 14.8 & 19.2 \\
\hline & Post stretch & -9.1 & -11.7 & -5.6 & -7.6 & -10.3 & -16.8 \\
\hline & & 4.5 & 6.0 & 9.8 & 11.3 & 10.9 & 12.2 \\
\hline & Post.far & 1.1 & -5.4 & 5.9 & 1.9 & -5.0 & -6.8 \\
\hline & & 3.4 & 7.1 & 7.4 & 8.2 & 10.7 & 12.9 \\
\hline & Post.very.far & -0.4 & -3.3 & -6.7 & -1.6 & -2.1 & 1.6 \\
\hline & & 4.3 & 9.6 & 12.0 & 10.0 & 11.9 & 12.7 \\
\hline & Post.remote & -9.6 & -3.5 & -5.7 & -7.1 & -4.8 & -8.5 \\
\hline & & 9.3 & 16.5 & 18.8 & 18.7 & 16.5 & 20.5 \\
\hline Tenure & & 1.4 & 0.0 & 0.3 & 0.6 & -0.1 & 1.0 \\
\hline & & 0.2 & 0.4 & 0.5 & 0.5 & 1.3 & 1.0 \\
\hline Control.sales & & 15.8 & 23.9 & 18.0 & 24.2 & 24.9 & 12.0 \\
\hline & & 1.0 & 1.8 & 2.0 & 2.1 & 3.8 & 3.2 \\
\hline
\end{tabular}


Two obstacles may prevent these salespeople from playing timing games. First, managers have regular one-on-one meetings ${ }^{9}$ to discuss where in the sales cycle all prospective customers are. This form of monitoring may make it difficult to delay the close of business because managers can infer delay tactics when future sales arrive. Furthermore, many of the managers have worked their way up through the ranks and have established personal relationships in their salespeople's accounts. If they suspect an employee is delaying orders, they may be able to directly contact customers and learn when the salesperson initiated the sales process. A monitoring explanation, however, does not account for why salespeople do not appear to be forward selling. Sales managers have no incentive to prevent this behavior, but we find no evidence of it either.

An explanation more consistent with the data is that the customers prevent timing games from being played in this industry. Spikes in market sales during the final month and dips during the first month of bonus periods bolster this idea. (The average values of the standardized CONTROL.SALES variable are 0.669 for the final months of a quarter and 1.61 for the final month of the year, whereas they are -0.430 for the first month of a quarter and -1.40 for the first month of the year.) Recall that the CONTROL.SALES variable was taken from an indirect channel that has no incentive to manipulate the timing of sales. A plausible explanation of the spikes and dips in these data is that customers require sales to close according to their own needs, perhaps making purchases only when enough money is available in their budgets at the end of a quarter. If this is the case, then salespeople face the prospect of either closing sales when the customers want them to close or losing them entirely, which precludes the salespeople from moving business across periods.

\subsection{Effort}

Support does exist for the idea that bonuses motivate salespeople to vary effort, and, on the whole, they motivate salespeople to work harder. Considered individually, the EXCEEDED and NEAR coefficients are positive and statistically significant for the quarterly periods, and the EXCEEDED, NEAR, STRETCH, and FAR coefficients are positive and statistically significant for the full-year period (see Table 7). Taken as a group, the $90 \%$ credible intervals for the weighted means are $(4.6,16.6)$ for the quarterly periods and $(52.2,73.0)$ for the full-year period. As both these intervals are strictly positive and all of the POST coefficients are insignificant, we claim that the incentive contract tends to motivate salespeople to work harder.

This is not to say that the bonuses only have productive effects. While the coefficients are not statistically significant, the estimates are negative for both of the REMOTE categories. This suggests that salespeople give up if they feel that they cannot make the quota. Even if we cannot interpret this as a marginal decrease in effort, we can certainly claim that these salespeople do not increase effort in an attempt to earn greater incentives. This supports the idea that salespeople react to the incentive contract in a rational manner.

How do the results based on individual output compare to the preliminary results based on sales-force output? The individual-level results provide even less evidence

\footnotetext{
${ }^{9}$ These meetings occur at least monthly and sometimes weekly.
} 
of timing games. The results for the quarterly bonus periods are consistent across the two analyses, and neither suggests that timing games occur. Spikes in revenue production at the end of the quarterly bonus periods are not followed by counterproductive dips in the subsequent period. The results for the full-year bonus period, however, are less consistent across the two analyses, and the individual-level results provide less evidence that the salespeople are playing timing games. In the preliminary analysis, we find evidence of forward selling because the spikes in revenue production at the end of the full-year bonus period are followed by dips in production in the subsequent period. In the individual-level analysis, we do not find statistically significant evidence of forward selling. Even if we were to use the weighted mean of the POST effects as a point estimate of the forward selling effects, it explains very little of the spike in revenue production. Since the weighted mean of the POST effects is -6.3 , and the weighted mean of the bonus period effects is 62.0 , we would estimate that about $10 \%$ of the increase is due to forward selling by this method.

Taken altogether, our results suggest that individual-level data are needed to determine the magnitude of timing and effort effects. As was seen in the preliminary analysis, the baseline sales level is crucial in accurately decomposing effort and timing effects, and the most appropriate baseline is an individual's sales level. Not accounting for heterogeneity in the intercepts is bound to bias the analysis. Furthermore, an individual's sales history determines which timing game is in her or his self-interest, and this history is lost if the data are aggregated.

\section{Conclusions and future research}

In this paper, we find that lump-sum bonuses motivate salespeople to work harder, not to play timing games - a result that is consistent with the widespread use of lump-sum bonuses in practice. This is not to suggest that lump-sum bonuses have no counterproductive effects. We find that bonuses cause some salespeople, those who are unlikely to make quota, to reduce effort, but this effect is more than compensated for by productive increases in output by other salespeople. Our results are based on a unique data source that contains the revenue production of individual salespeople. Using these data, we bring into question whether models based on aggregate data sources can accurately decompose effort and timing effects and cast doubt on previous findings that suggest the primary effect of lump-sum bonuses is to induce salespeople to play timing games.

This study also provides a basis for future research. We are currently addressing the issue of how firms should design optimal incentive contracts - combining sales quotas, bonuses, and commission rates to effectively motivate their sales forces. This and other studies that explore policy variation need to make assumptions about how individuals will behave when policies are changed. Our current findings suggest that salespeople will alter how hard they work, but will not manipulate the timing of orders in response to incentive contracts. Having identified the key ingredients to a structural model of salespeople's behavior, we can now pursue questions of how to effectively motivate them. 


\section{Appendix I. The effort model}

First, let us consider a salesperson who has been successful in the first two periods. This person's expected utility is

$$
\begin{aligned}
& \theta_{3}\left[u(a+b)-\theta_{3 / 2}^{2}-\frac{1}{2} \sum_{t=1}^{2} \theta_{t}^{2}\right]+\left(1-\theta_{3}\right)\left[u(a+b)-\theta_{3 / 2}^{2}-\frac{1}{2} \sum_{t=1}^{2} \theta_{t}^{2}\right] \\
& =\left[u(a+b)-\theta_{3 / 2}^{2}-\frac{1}{2} \sum_{t=1}^{2} \theta_{t}^{2}\right]
\end{aligned}
$$

because the bonus is earned whether the salesperson is successful or not. Taking the first derivative of expected utility with respect to $\theta_{3}$ results in the first-order condition that $\theta_{3}=0$. No additional gain comes from working, so the salesperson chooses not to do so. Letting $\theta_{3 \mid S_{2}=s}$ represent the effort put in the third period if the salesperson's accumulated sales after the second period is $s$, we find $\theta_{3 \mid S_{2}=2}=0$. The salesperson's expected utility is $u(a+b)-\frac{1}{2} \sum_{t=1}^{2} \theta_{t}^{2}$ if this decision node is reached.

A similar argument holds for a salesperson who has not completed a sale in the first two periods. This person's expected utility is

$$
\left[u(a)-\theta_{3 / 2}^{2}-\frac{1}{2} \sum_{t=1}^{2} \theta_{t}^{2}\right]
$$

because the bonus is not earned whether the salesperson is successful in the third period or not. Thus, $\theta_{3 \mid S_{2}=0}=0$ and the salesperson's expected utility is $u(a)-\frac{1}{2}$ $\sum_{t=1}^{2} \theta_{t}^{2}$ if this decision node is reached.

Now, let us consider a salesperson who has completed one sale after two periods. This person's expected utility is

$$
\begin{aligned}
& \theta_{3}\left[u(a+b)-\theta_{3 / 2}^{2}-\frac{1}{2} \sum_{t=1}^{2} \theta_{t}^{2}\right]+\left(1-\theta_{3}\right)\left[u(a)-\theta_{3 / 2}^{2}-\frac{1}{2} \sum_{t=1}^{2} \theta_{t}^{2}\right] \\
& =u(a)+\theta_{3}[u(a+b)-u(a)]-\theta_{3 / 2}^{2}-\frac{1}{2} \sum_{t=1}^{2} \theta_{t}^{2}
\end{aligned}
$$

because the bonus is earned only if the salesperson is successful in the last period. Thus, the first-order condition for a maximum is $[u(a+b)-u(a)]-\theta_{3}=0$. For convenience, define the change in utility for earning the bonus as $\Delta=$ $u(a+b)-u(a)$. Thus, $\theta_{3 \mid S_{2}=2}=\Delta$ (positive effort is exerted to earn the bonus) and the salesperson's expected utility is $u(a)+\frac{1}{2} \Delta^{2}-\frac{1}{2} \sum_{t=1}^{2} \theta_{t}^{2}$ if this decision node is reached. We assume the firm chooses a bonus $b$ such that $\Delta \leq 1$; that is, the bonus is set at a reasonable, not an extraordinarily high, level. Otherwise the firm would be overpaying for the chance of a certain sale in this period. Since $a>0, b>0$, $0<\Delta \leq 1$.

The question is how do the third period strategies compare to the second period strategies? 
Let us first consider a salesperson who completed a sale in the first period. The expected utility of this person is

$$
\begin{aligned}
& \theta_{2}\left[u(a+b)-\frac{1}{2} \sum_{t=1}^{2} \theta_{t}^{2}\right]+\left(1-\theta_{2}\right)\left[u(a)+\frac{1}{2} \Delta^{2}-\frac{1}{2} \sum_{t=1}^{2} \theta_{t}^{2}\right] \\
& =u(a)+\theta_{2} \Delta+\frac{1-\theta_{2}}{2} \Delta^{2}-\frac{1}{2} \sum_{t=1}^{2} \theta_{t}^{2}
\end{aligned}
$$

The first order condition for a maximum is $\Delta-\frac{\Delta^{2}}{2}-\theta_{2}=0$, which implies $\theta_{2 \mid S_{1}=1}=\Delta-\frac{\Delta^{2}}{2}$.

Now consider a salesperson who did not complete a sale in the first period. This person's expected utility is

$$
\begin{aligned}
& \theta_{2}\left[u(a)+\frac{1}{2} \Delta^{2}-\frac{1}{2} \sum_{t=1}^{2} \theta_{t}^{2}\right]+\left(1-\theta_{2}\right)\left[u(a)-\frac{1}{2} \sum_{t=1}^{2} \theta_{t}^{2}\right] \\
& =u(a)+\frac{\theta_{2} \Delta^{2}}{2}-\frac{1}{2} \sum_{t=1}^{2} \theta_{t}^{2}
\end{aligned}
$$

The first order condition for a maximum is $\frac{\Delta^{2}}{2}-\theta_{2}=0$, which implies $\theta_{2 \mid S_{1}=0}=\frac{\Delta^{2}}{2}$.

Since $\theta_{3 \mid S_{2}=1}=\Delta>\frac{\Delta^{2}}{2}=\theta_{2 \mid S_{1}=0}$ and $\theta_{3 \mid S_{2}=1}=\Delta>\Delta-\frac{\Delta^{2}}{2}=\theta_{2 \mid S_{1}=1}$ when $0<\Delta \leq 1$, the salesperson, if it is necessary to stretch to make the quota, marginally increases effort in the third period.

Since $\theta_{3 \mid S_{2}=2}=0<\Delta-\frac{\Delta^{2}}{2}=\theta_{2 \mid S_{1}=1}$, the salesperson, if the quota has already been made, marginally decreases effort in the third period.

Since $\theta_{3 \mid S_{2}=0}=0<\frac{\Delta^{2}}{2}=\theta_{2 \mid S_{1}=0}$, the salesperson, if the quota has already been made, marginally decreases effort in the third period.

\section{Appendix II. The full conditional distributions}

Assume conjugate prior distributions

$$
\begin{aligned}
{\left[\sigma_{s i}^{2}\right] } & =\left[\sigma_{\alpha s}^{2}\right]=\left[\sigma_{\xi}^{2}\right]=G\left[v_{0} / 2, \lambda_{0} / 2\right] & {\left[\sum^{-1}\right] } & =W\left(\rho_{0} I_{p}, \rho_{0}\right) \\
{[\gamma] } & =N\left(0, \tau_{0}^{2}\right) & {[\delta] } & =\operatorname{MVN}_{p}\left(0, T_{0}\right)
\end{aligned}
$$

For notational convenience, define

$$
\begin{array}{rlrl}
d_{s i} & =n_{s i} \sigma_{s i}^{-2}+\sigma_{\alpha s}^{-2} & D_{s} & =\sum_{i=1}^{n_{s}} \sigma_{s i}^{-2} X_{s i}^{T} X_{s i}+\sum^{-1} \\
d_{s} & =n_{s} \sigma_{\alpha s}^{-2}+\sigma_{\xi}^{-2} & D & =c \sum^{-1}+T_{0}^{-1} \\
d & =c \sigma_{\xi}^{-2}+\tau_{0}^{-2} & &
\end{array}
$$


The full conditional distributions resulting from these assumptions are

$$
\begin{aligned}
{\left[\sigma_{s i}^{-2} \mid y_{s i t}, \alpha_{s i}, \beta_{s}\right] } & =G\left(\frac{v_{0}+n_{s i}}{2}, \frac{\lambda_{0}+\sum_{t=1}^{n_{s i}}\left(y_{s i t}-\alpha_{s i}-X_{s i t} \beta_{s}\right)^{2}}{2}\right) \\
{\left[\alpha_{s i} \mid y_{s i t}, \beta_{s}, \sigma_{s i}^{-2}, \xi_{s}, \sigma_{\alpha s}^{-2}\right] } & =N\left(d_{s i}^{-1}\left[\sigma_{s i}^{-2} \sum_{t=1}^{n_{s i}}\left(y_{s i t}-X_{s i t} \beta_{s}\right)+\sigma_{\alpha s}^{-2} \xi_{s}\right], d_{s i}^{-1}\right) \\
{\left[\sigma_{\alpha s}^{-2} \mid \alpha_{s i}, \xi_{s}\right] } & =G\left(\frac{v_{0}+n_{s}}{2}, \frac{\lambda_{0}+\sum_{i=1}^{n_{s}}\left(\alpha_{s i}-\xi_{s}\right)^{2}}{2}\right) \\
{\left[\xi_{s} \mid \alpha_{s i}, \sigma_{\alpha s}^{-2}, \gamma, \sigma_{\xi}^{-2}\right] } & =N\left(d_{s}^{-1}\left[\sigma_{\alpha s}^{-2} \sum_{i=1}^{n_{s}} \alpha_{s i}+\sigma_{\xi}^{-2} \gamma\right], d_{s}^{-1}\right) \\
{\left[\sigma_{\xi}^{-2} \mid \xi_{s}, \gamma\right] } & =G\left(\frac{v_{0}+c}{2}, \frac{\lambda_{0}+\sum_{s=1}^{c}\left(\xi_{s}-\gamma\right)^{2}}{2}\right) \\
{\left[\gamma \mid \xi_{s}, \sigma_{\xi}^{-2}\right] } & =N\left(d^{-1}\left[\sigma_{\xi}^{-2} \sum_{s=1}^{c} \xi_{s}\right], d^{-1}\right) \\
{\left[\beta_{s} \mid y_{s i t}, \alpha_{s i}, \sigma_{s i}^{-2}, \delta, \sum^{-1}\right] } & =M V N_{p}\left(D_{s}^{-1}\left(\sum_{i=1}^{n_{s}} \sigma_{s i}^{-2} X_{s i}^{T}\left(y_{s i}-\alpha_{s i} l_{n_{s i}}\right)+\sum^{-1} \delta\right), D_{s}^{-1}\right) \\
{\left[\sum^{-1} \mid \delta, \beta_{s}\right] } & =W\left(\sum_{s=1}^{c}\left(\beta_{s}-\delta\right)\left(\beta_{s}-\delta\right)^{T}+\rho_{0} I_{p}, c+\rho_{0}\right) \\
{\left[\delta \mid \beta_{s}, \sum^{-1}\right] } & =M V N_{p}\left(D^{-1}\left(\sum^{-1} \sum_{s=1}^{c} \beta_{s}\right), D^{-1}\right)
\end{aligned}
$$

\section{References}

"Finding the Compensation Plan that Works Best," Agency Sales Magazine (September 2001)

"Inspire Your Employees: Give Them Bonuses," Bottomline (October 1986)

Banker, R. D., Lee, S. Y., Potter, G., \& Srinivasan, D. (2000). An empirical analysis of continuing improvements following the implementation of a performance-based compensation plan. Journal of Accounting and Economics, $X X X(3), 315-350$ (December).

Basu, A. K., Lal, R., Srinivasan, V., \& Staelin, R. (1985). Sales force compensation plans: an agency theoretical perspective. Marketing Science, IV(4), 267-291.

Chevalier, J., \& Ellison, G. (1997). Risk taking by mutual funds as a response to incentives. Journal of Political Economy, CV(6), 1167-1200.

Churchill, G. A., Ford, N. M., Walker, O. C., Johnston, M. W., \& Tanner, J. F. (2000). Sales force Management, Sixth Edition. Irwin/McGraw-Hill.

Coughlan, A. T., \& Narasimhan, C. (1992). An empirical analysis of sales-force compensation plans. Journal of Business, LXV(1), 93-121.

Coughlan, A. T., \& Sen, S. K. (1986). Sales force Compensation: Insights from Management Science. Marketing Science Institute Report No. 86-101, Cambridge, Massachusetts.

Darmon, R. (1997). Selecting appropriate sales quota plan structures and quota-setting procedures. Journal of Personal Selling and Sales Management, XVII(1), 1-16.

Gaba, A., \& Kalra, A. (1999). Risk behavior in response to quotas and contests. Marketing Science, XVIII (3), 417-434.

Godes, D. (2004). Contracting under endogenous risk. Quantitative Marketing and Economics, II(4), 321345.

Gupta, S. (1988). The impact of sales promotions on when, what and how much to buy. Journal of Marketing Research, XXV(4), 342-355.

Healy, P. M. (1985). The effect of bonus schemes on accounting decisions. Journal of Accounting and Economics, VII, 85-107.

Holmstrom, B., \& Milgrom, P. (1987). Aggregation and linearity in the provision of intertemporal incentives. Econometrica, LV, 303-328 (March).

Hull, C. L. (1932). The goal-gradient hypothesis and maze learning. The Psychological Review, 39, $25-43$.

Hull, C. L. (1938). The goal-gradient hypothesis applied to some 'Field-Force' problems in the behavior of young children. The Psychological Review, XLV(4), 271-298. 
Jensen, M. C. (2003). Paying people to lie: the truth about the budgeting process. European Financial Management, $I X, 379-406$.

John, G., \& Weitz, B. (1989). Sales force compensation: an empirical investigation of factors related to use of salary versus incentive compensation. Journal of Marketing Research, XXVI, 1-14.

Joseph, K., \& Kalwani, M. (1998). The role of bonus pay in sales force compensation plans. Industrial Marketing Management, XXVII, 147-159.

Joseph, K., \& Thevaranjan, A. (1998). Monitoring incentives in sales organizations: an agency-theoretic perspective. Marketing Science, XVII(2), 107-123.

Lal, R., \& Srinivasan, V. (1993). Compensation plans for single-and multi-product sales forces: an application of the Holmstrom-Milgrom Model. Management Science, XXXIX(7), 777-793.

Latham, G. P., \& Locke, E. A. (1991). Self-regulation through goal setting. Organizational Behavior and Human Decision Processes, L, 212-247.

Lazear, E. P. (2000). Performance pay and productivity. American Economic Review, XC(5), 1346-1361.

Mace, C. A. (1935). Incentives: some experimental studies," Report No. 72 (Great Britain: Industrial Health Research Board).

Mantrala, M. K., Sinha, P., \& Zoltners, A. A. (1994). Structuring a multiproduct sales quota-bonus plan for a heterogeneous sales force: a practical model based approach. Marketing Science, XIII(2), 121144.

McFarland, R. G., Challagalla, G. N., \& Zenor, M. J. (2002). The effect of single and dual sales targets on sales call selection: quota versus quota and bonus plan. Marketing Letters, XIII(2), 107-120.

Misra, S., Coughlan, A. T., \& Narasimhan, C. (2005). Salesforce compensation: an analytical and empirical examination of the agency theoretic approach. Quantitative Marketing and Economics, III (1), 5-39.

Moynahan, J. K. (1980). Designing an effective sales compensation program. New York, NY: AMACOM.

Oyer, P. (1998). Fiscal year ends and nonlinear incentive contracts: the effect on business seasonality. Quarterly Journal of Economics, CXIII(1), 149-185.

Rao, R. (1990). Compensating heterogeneous sales forces: some explicit solutions. Marketing Science, $I X$ (4), 319-341.

Steenburgh, T. J. (2007). Measuring consumer and competitive impact with elasticity decompositions. Journal of Marketing Research, XLIV(4), 636-646.

Van Heerde, H. J., Gupta, S., \& Wittink, D. (2003). Is $75 \%$ of the sales promotion bump due to brand switching? No, only 33\% is. Journal of Marketing Research, XL(4), 383-395. 